\title{
RESEARCH
}

Open Access

\section{The role of leukotriene modifying agent treatment in neuropsychiatric events of elderly asthma patients: a nested case control study}

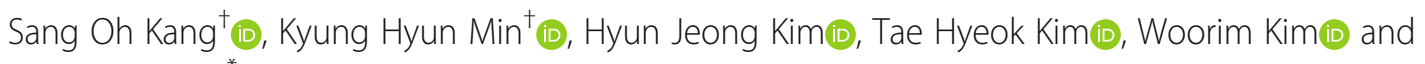
Kyung Eun Lee*

\begin{abstract}
Background: In March 2020, the US Food and Drug Administration decided that the dangers related to neuropsychiatric events (NPEs) of montelukast, one of the leukotriene modifying agents (LTMAs), should be communicated through 'boxed warning'. In case of NPEs, the prevalence has been the highest in elderly people. Because the characteristics of the elderly such as old age itself can act as risk factors. Therefore, an investigation on safety of LTMAs related to NPEs in elderly using LTMAs is needed.

Method: A nested case-control study using an elderly sample cohort from the Korean National Health Insurance Service database was used. The asthma cohort included asthma patients newly diagnosed between 2003 and 2013. Within the asthma cohort, the case group was defined as patients who were diagnosed with NPEs. Among patients who had never been diagnosed with NPEs, the control group was selected by matching 1:1 by propensity score. Patients who were prescribed LTMAs for 1 year prior to index date were defined as the exposure group. The logistic regression model was used to measure the effect of LTMAs on NPEs.

Results: We identified 141,165 patients with newly diagnosed asthma, and selected 31,992 patients per each case and control group. Exposure to LTMAs significantly increased the risk of overall NPEs about in comparison with the absence of exposure (crude odds ratio [OR] 1.58, 95\% Cl 1.50-1.68). After adjusting for confounding factors, the overall NPEs risk increased (adjusted OR, 1.67, 95\% Cl 1.58-1.78).

(Continued on next page)
\end{abstract}

\footnotetext{
* Correspondence: kaylee@cbnu.ac.kr

${ }^{+}$Sang Oh Kang and Kyung Hyun Min contributed equally to this work. College of Pharmacy, Chungbuk National University, 660-1 Yeonje-ri,

Osong-eup, Heungdeok-gu, Cheongju-si 28160, Republic of Korea
}

(c) The Author(s). 2021 Open Access This article is licensed under a Creative Commons Attribution 4.0 International License, which permits use, sharing, adaptation, distribution and reproduction in any medium or format, as long as you give appropriate credit to the original author(s) and the source, provide a link to the Creative Commons licence, and indicate if changes were made. The images or other third party material in this article are included in the article's Creative Commons licence, unless indicated otherwise in a credit line to the material. If material is not included in the article's Creative Commons licence and your intended use is not permitted by statutory regulation or exceeds the permitted use, you will need to obtain permission directly from the copyright holder. To view a copy of this licence, visit http://creativecommons.org/licenses/by/4.0/ The Creative Commons Public Domain Dedication waiver (http://creativecommons.org/publicdomain/zero/1.0/) applies to the data made available in this article, unless otherwise stated in a credit line to the data. 
(Continued from previous page)

Conclusion: This study suggests that elderly asthma patients prescribed LTMAs had a higher risk of NPEs than patients who were not treated with LTMAs. Therefore, clinicians should be aware of the potential risks of LTMAs.

Keywords: Leukotriene modifying agent, Neuropsychiatric events, National health insurance service database, South Korea, Asthma, Nested case-control study

\section{Background}

Asthma is the most common chronic airway disease that affected approximately 358 million patients in 2015 globally [1]. It is characterized by chronic airway inflammation and recurring symptoms such as wheezing, dyspnea, chest-tightness, and coughing [2]. Asthma is typically managed with a combination of long-term maintenance therapy (controller medications) and short-term therapy for the relief of acute asthma symptoms (reliever medications) [3]. Leukotriene modifying agents (LTMAs), including montelukast, pranlukast and zafirlukast, are one of the maintenance medications [4]. These agents function by chemically modifying and inhibiting an inflammatory mediator called leukotriene, which causes longlasting bronchoconstriction and increases mucus production. These agents can be used to improve lung function and decrease the requirement for $\beta$ adrenergic agonists, resulting in significant symptom control [5].

In 2009, the US Food and Drug Administration (FDA) announced a label change for montelukast to include a warning regarding neuropsychiatric events (NPEs) under the "Precautions" section. This label change was triggered by post-marketing case reports to the FDA Adverse Event Reporting System. Specifically, patients prescribed montelukast reported episodes of depression, anxiety, sleep disturbance, aggression/agitation, suicidal ideation, suicide attempts, and/or completed suicide [6]. FDA continued to receive case reports of mental health side effects associated with montelukast use and conducted an observational study using data from its Sentinel System. Consistent with the prior evaluations of FDA, a wide variety of mental health side effects were found (including completed suicides). Some occurred during montelukast treatment and resolved after stopping the medicine. Thus, in March 2020, the FDA announced that montelukast required a Black Boxed Warning, their most prominent warning [7].

In Korea, there were nearly 2.22 millon of asthma patients in 2010 and the prevalence of asthma was high, especially in the population aged over 60 years. The percentage of LTMAs among prescribed anti-asthma drugs has been growing (26.2\% in 2002 and $63.1 \%$ in 2015 in uncontrolled asthma; $46.4 \%$ in 2002 and $76.4 \%$ in 2015 in severe asthma) [8]. Also, the data suggest increasing use of LTMAs in elderly asthma patients.

The elderly are more vulnerable to NPEs than the general population. As well as, the prevalence of NPEs such as depression and sleep disorder is higher in the elderly $[9,10]$. Despite the FDA regulation on using montelukast, studies including elderly asthma patients or examining the association of NPEs in other LTMAs are scarce.

Therefore, we aimed to investigate whether LTMA use was associated with the risk of NPE development and also to examine if this is a class effect of LTMAs, especially in elderly asthma patients by using large population database.

\section{Methods}

\section{Data source}

This is a nested case-control study using the Korean National Health Insurance Service (NHIS) elderly cohort data. NHIS database contains medical claims data for more than $99 \%$ of the South Korean population and has long-period of follow up. It contains individual beneficiary and healthcare service information including diagnoses, procedures, and prescriptions. The information on diagnoses were coded according to the International Classification of Diseases, Tenth Revision (ICD-10).

The NHIS elderly database contains stratified random samples of claims data, and the size of the samples was calculated and data were extracted on a yearly basis to improve the representativeness of the sociodemographic characteristics, diagnosis, and healthcare services including prescription drugs for Korean patients. The National Health Insurance program in Korea has provided a comprehensive elderly cohort database that supports researches on analysis of the risk factors of prevalent diseases and prognosis in elderly patients.

\section{Study samples and design Nested case-control study}

A nested case control study was used to investigate the association between LTMA treatment and diagnosis of NPEs. 'Nested' means that subjects included in a defined cohort become baseline patients for the selection of the case and control. In a retrospective nested case-control study such as this study, a case, affected by the disease, 
is matched with one or more individuals not affected by the disease, the controls [11].

\section{Asthma subjects}

The asthma subjects included elderly cohort (aged over 60) who were newly diagnosed with asthma (ICD-10, J45) or status asthmaticus (ICD-10, J46) between 2003 and 2013 and had been prescribed an asthma disease controller [12] (inhalers: budesonide, ciclesonide, fluticasone, beclomethasone, beclomethasone/formoterol, budesonide/formoterol, fluticasone/formoterol, fluticasone/vilanterol, fluticasone/ salmeterol, tablets: bambuterol, salbutamol, theophylline, aminophylline, doxofylline, montelukast, zafirlukast, pranlukast).

\section{Case and control group definition}

Among asthma subjects, the case group was defined as patients who were diagnosed with NPEs. The NPEs included mood disorder, sleep disorder, anxiety disorder, personality disorder, substance-related disorder, agitation, schizophrenia and self-harm disease. These NPEs were in accordance with neuropsychiatric diagnosis mentioned in the montelukast product label [13]. Index date of the case group was defined as the date of NPE diagnosis. Patients who were diagnosed with NPEs before asthma diagnosis were excluded from the case group.

Control group was defined as patients who had never been diagnosed with NPEs and was matched by propensity score considering sex, age, income level and comorbidities. The index date of the control group was selected as a random date between the patient's first and last diagnosis date of any diseases in the NHIS database (December 31th, 2013). (Fig. 1).

\section{Exposure to LTMAs}

Patients who were prescribed LTMAs including montelukast, pranlukast or zafirlukast during asthma drug exposure period were defined as the exposure group. The drug exposure period was defined as 1 year before the index date.

"Recency of exposure" was the number of days between the last day of LTMA exposure in the drug exposure period and the index date, and was categorized into 1-60 days, 61-120 days, and 121-365 days. These recency of exposure subgroups were named group 1, group 2, and group 3, respectively.

"Duration of exposure" was defined as the total days of LTMA prescription in the drug exposure period and was categorized into 1-30 days, 31-120 days and greater than 120 days. These exposure duration subgroups were named as group 4, group 5 and group 6, respectively.

\section{Variables for adjusting confounders}

The following variables were considered when subjects were enrolled. The baseline demographic variables included age, sex, income level, comorbidities, and Charlson Comorbidity Index (CCI). CCI was used to calculate the severity of health status [14] and to consider the effect of comorbidities on NPE development. CCI includes of 15 categories of diseases that can predict the 1-year death rate: myocardial infarction, congestive heart failure, peripheral vascular disease, cerebrovascular disease, dementia, chronic pulmonary disease, rheumatologic disease, peptic ulcer

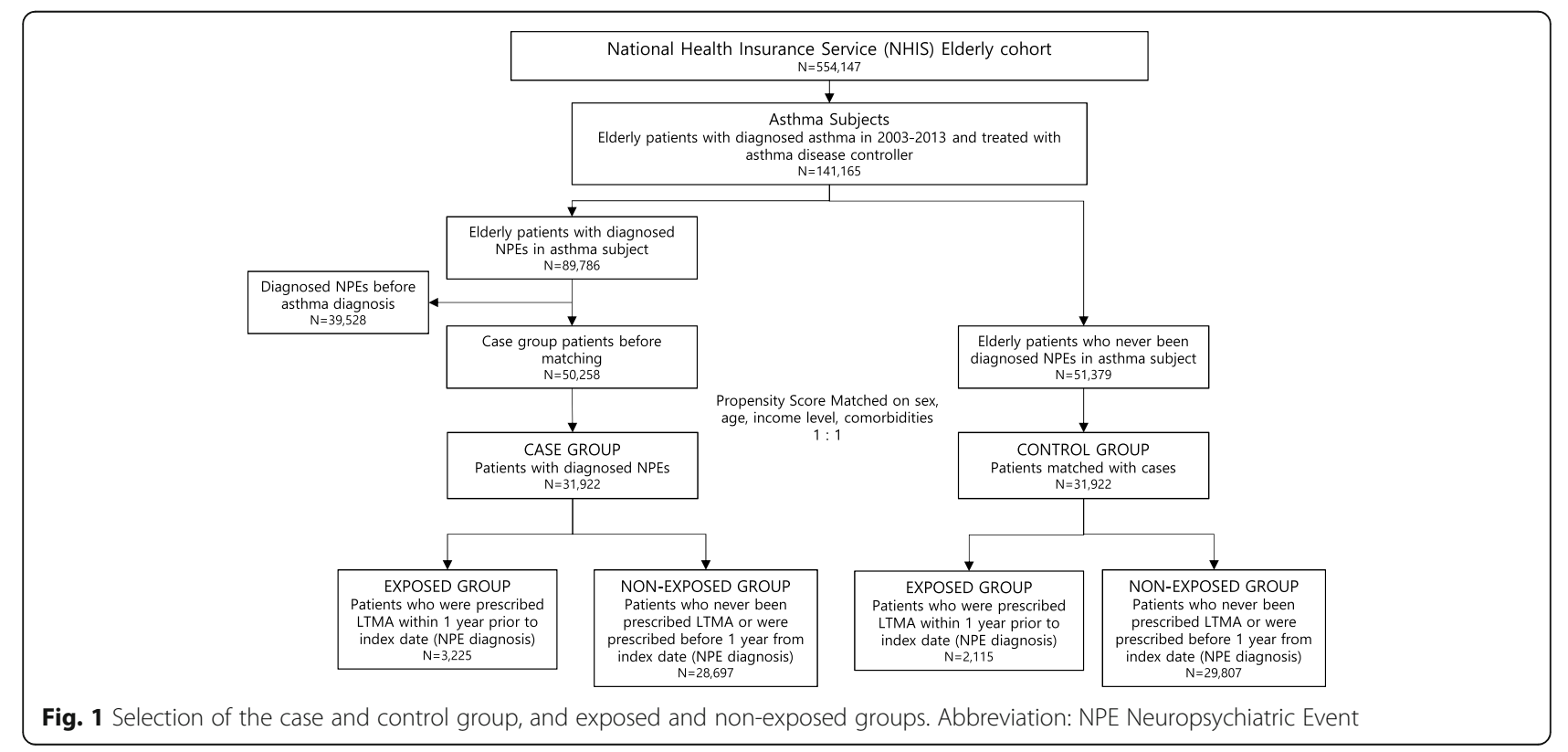


disease, liver disease, diabetes mellitus, hemiplegia or paraplegia, renal disease, malignancies including metastatic solid tumors, and AIDS. Additionally, hypertension, dyslipidemia, arrhythmia and Parkinson's disease were included as covariates and because there is evidences of their association with NPEs $[15,16]$.

\section{Statistical analysis}

A chi-square test was performed for categorical variables and a two-sample $t$-test was performed for continuous variables to evaluate the difference between the case and control groups. The logistic regression model was used to measure the effect of LTMAs on NPEs in two ways. Model 1 was logistic regression conducted with only LTMA exposure. Model 2 was adjusted regression with demographic covariates.

First, we categorized regression by the type of NPEs (overall NPEs, sleep disorder, mood disorder, anxiety disorder). Second, we categorized overall NPE regression into three types by sex (total, male, female). Third, we categorized four types of NPE regression into recency of exposure and treatment duration. All data analyses were performed using SAS version 9.4 (SAS Institute Inc. Cary, NC, USA) and statistical significance was inferred at a two-sided $p$-value of $<0.05$.

\section{Results}

Baseline characteristics of the case and control groups Among 554,147 elderly patients, we identified 141,165 patients who were newly diagnosed with asthma and were prescribed an anti-asthmatic drug between 2003 and 2013. In this senior asthma cohort, 31,992 patients diagnosed with NPEs were selected as the case group.

New-onset NPEs occurred more often in females (58.6\% in the case and control groups) and nearly 50\% of patients were in their 70 s $(47.7 \%$ in the case group; $48.4 \%$ in the control group). Exposure to LTMAs was more common in the case group (3225 cases, 10.1\%) than in the control group (2115 cases, 6.6\%). Most of the baseline characteristics were well balanced between the two groups. There were no significant differences in age, sex, income level and most comorbidities, although several comorbidities (dementia, hypertension, peripheral vascular disease and chronic pulmonary disease) had a significant association with NPE development between the two groups. (Table 1).

The most frequently prescribed LTMA was montelukast $(1788 / 3225,55.4 \%$ in the case group; $1243 / 2115$, $58.8 \%$ in the control group), followed by pranlukast (1409/3225, 43.7\% in the case group; $853 / 2115,40.3 \%$ in the control group), and zafirlukast $(28 / 3225,0.9 \%$ in the case group; $19 / 2115,0.9 \%$ in the control group).

\section{Neuropsychiatric events in LTMA users}

Univariate and multivariate conditional logistic regression were used to estimate the risk of overall NPEs and three most frequent NPEs. Exposure to LTMAs was significantly associated with 1.58 times increased odds of NPEs in the unadjusted model (crude OR, 1.58; 95\% CI 1.50-1.68). Similarly, for the three most frequent NPEs (sleep disorder, mood disorder and anxiety disorder), the odds of NPEs increased 1.49-1.53 times. (sleep disorder; 1.50, 95\% CI 1.38-1.63; mood disorder; 1.49 , 95\% CI 1.37-1.63; anxiety disorder; 1.53 , 95\% CI 1.41-1.66). After controlling for covariates that were included in baseline characteristics in Table 1, the overall risk of NPEs in patients treated with LTMAs was also increased by nearly $70 \%$ compared to non-exposed patients (adjusted OR 1.67, 95\% CI 1.58-1.78). Furthermore, LTMA treatment was associated with higher OR compared to no LTMA exposure for sleep disorder (1.54, 95\% CI 1.42-1.68), mood disorder (1.65, 95\% CI $1.51-1.81)$, and anxiety disorder, $(1.63,95 \%$ CI 1.50-1.77) (Table 2).

\section{NPE risk by recency of exposure}

The overall risk of NPEs and of the three NPEs was increased in all subgroups categorized by recency of exposure. In early period ( $<60$ days, group 1$)$, the overall risk of NPEs was the highest in both the unadjusted and adjusted models. In the adjusted model, the overall risk of NPEs was almost twice than in LTMA non-exposed group (crude OR in group 1, 1.88, 95\% CI 1.72-2.07; adjusted OR in group $1,1.99,95 \%$ CI 1.81-2.18). The overall risk of NPEs decreased gradually in both models. In the late period ( $>120$ days, group 3 ), the overall risk of NPEs was the lowest (crude OR in group 3, 1.38, 95\% CI 1.27-1.50; adjusted OR in group 3; $1.46,95 \%$ CI 1.34-1.59) (Table 3).

\section{NPE risk by duration of exposure}

We classified patients who were exposed to LTMAs into three subgroups by duration of treatment. The risk of overall NPEs in patients treated for $31-120$ days was the highest among the three subgroups.

The risk of overall NPEs was the lowest when patients used LTMA for more than 120 days (group 6) in both the unadjusted and adjusted models (crude OR, 1.51, 95\% CI 1.31-1.75; adjusted OR, 1.60, 95\% CI 1.38-1.85). In analyses of the three NPEs, the risk of every NPE had the highest OR in patients treated for $31-120$ days in both unadjusted model and adjusted models (Table 4).

\section{Discussion}

Our research was conducted to assess the risk of NPEs in elderly asthma patients who were treated with 
Table 1 Baseline demographic characteristics

\begin{tabular}{|c|c|c|c|}
\hline & $\begin{array}{l}\text { CASE group } \\
\text { (NPE development) }\end{array}$ & $\begin{array}{l}\text { CONTROL group } \\
\text { (No NPE development) }\end{array}$ & $P$ value \\
\hline \multicolumn{4}{|l|}{ Sex } \\
\hline Male & $13,206(41.4 \%)$ & $13,221(41.4 \%)$ & \multirow[t]{2}{*}{0.90} \\
\hline Female & $18,716(58.6 \%)$ & $18,701(58.6 \%)$ & \\
\hline Age, mean (SD) & $72.7(6.6)$ & $72.6(6.6)$ & 0.11 \\
\hline \multicolumn{4}{|l|}{ Age group } \\
\hline $60 \mathrm{~s}$ & $11,483(36.0 \%)$ & 11,459 (35.9\%) & \multirow[t]{4}{*}{0.10} \\
\hline $70 \mathrm{~s}$ & $15,227(47.7 \%)$ & $15,440(48.4 \%)$ & \\
\hline $80 \mathrm{~s}$ & $4824(15.1 \%)$ & $4619(14.5 \%)$ & \\
\hline $90 \mathrm{~s}$ & $388(1.2 \%)$ & $404(1.3 \%)$ & \\
\hline \multicolumn{4}{|l|}{ Income level } \\
\hline Q0-Q2 & $8248(25.8 \%)$ & 8038 (25.2\%) & \multirow[t]{4}{*}{0.11} \\
\hline Q3-Q5 & 5465 (17.1\%) & $5643(17.7 \%)$ & \\
\hline Q6-Q8 & $8046(25.2 \%)$ & $8117(25.4 \%)$ & \\
\hline Q9-Q10 & $10,163(31.8 \%)$ & $10,124(31.7 \%)$ & \\
\hline \multicolumn{4}{|l|}{ LTMA use } \\
\hline Yes & $3225(10.1 \%)$ & $2115(6.6 \%)$ & \multirow[t]{2}{*}{$<0.01$} \\
\hline No & 28,697 (89.9\%) & 29,807 (93.4\%) & \\
\hline \multicolumn{4}{|l|}{ Comorbidities } \\
\hline CCl score, mean (SD) & $2.52(2.14)$ & $2.51(2.19)$ & 0.55 \\
\hline Group 1 (0) & $3320(10.4 \%)$ & $3489(10.9 \%)$ & \multirow[t]{3}{*}{0.06} \\
\hline Group $2(2 \geq c c i \geq 1)$ & $16,161(50.6 \%)$ & $16,173(50.7 \%)$ & \\
\hline Group 3 (cci $\geq 3$ ) & 12,441 (39.0\%) & $12,260(38.4 \%)$ & \\
\hline \multicolumn{4}{|l|}{ Myocardial infarction } \\
\hline Yes & $971(3.0 \%)$ & $935(2.9 \%)$ & \multirow[t]{2}{*}{0.40} \\
\hline No & $30,951(97.0 \%)$ & 30,987 (97.1\%) & \\
\hline \multicolumn{4}{|l|}{ Congestive heart failure } \\
\hline Yes & $3610(11.3 \%)$ & $3560(11.1 \%)$ & \multirow[t]{2}{*}{0.53} \\
\hline No & 28,312 (88.7\%) & 28,362 (88.9\%) & \\
\hline \multicolumn{4}{|l|}{ Arrhythmia } \\
\hline Yes & $2131(6.7 \%)$ & $2070(6.5 \%)$ & \multirow[t]{2}{*}{0.33} \\
\hline No & $29,791(93.3 \%)$ & $29,852(93.5 \%)$ & \\
\hline \multicolumn{4}{|l|}{ Hypertension } \\
\hline Yes & $19,563(61.3 \%)$ & $19,882(62.3 \%)$ & \multirow[t]{2}{*}{$<0.01$} \\
\hline No & 12,359 (38.7\%) & 12,040 (37.7\%) & \\
\hline \multicolumn{4}{|l|}{ Dyslipidemia } \\
\hline Yes & $9630(30.2 \%)$ & $9510(29.8 \%)$ & \multirow[t]{2}{*}{0.30} \\
\hline No & $22,292(69.8 \%)$ & $22,412(70.2 \%)$ & \\
\hline \multicolumn{4}{|c|}{ Peripheral vascular disease } \\
\hline Yes & $5080(15.9 \%)$ & $4892(15.3 \%)$ & \multirow[t]{2}{*}{0.04} \\
\hline No & $26,842(84.1 \%)$ & $27,030(84.7 \%)$ & \\
\hline \multicolumn{4}{|l|}{ Cerebrovascular disease } \\
\hline Yes & $5289(16.6 \%)$ & $5108(16.0 \%)$ & \multirow[t]{2}{*}{0.05} \\
\hline No & $26,633(83.4 \%)$ & $26,814(84.0 \%)$ & \\
\hline
\end{tabular}


Table 1 Baseline demographic characteristics (Continued)

\begin{tabular}{|c|c|c|c|}
\hline & $\begin{array}{l}\text { CASE group } \\
\text { (NPE development) }\end{array}$ & $\begin{array}{l}\text { CONTROL group } \\
\text { (No NPE development) }\end{array}$ & $P$ value \\
\hline \multicolumn{4}{|c|}{ Dementia } \\
\hline Yes & $1745(5.5 \%)$ & $1495(4.7 \%)$ & \multirow[t]{2}{*}{$<0.01$} \\
\hline No & $30,177(94.5 \%)$ & $30,427(95.3 \%)$ & \\
\hline \multicolumn{4}{|c|}{ Parkinson's disease } \\
\hline Yes & $422(1.3 \%)$ & $374(1.2 \%)$ & \multirow[t]{2}{*}{0.09} \\
\hline No & $31,500(98.7 \%)$ & $31,548(98.8 \%)$ & \\
\hline \multicolumn{4}{|c|}{ Chronic pulmonary disease } \\
\hline Yes & $19,022(59.6 \%)$ & 19,449 (60.9\%) & \multirow[t]{2}{*}{$<0.01$} \\
\hline No & $12,900(40.4 \%)$ & 12,473 (39.1\%) & \\
\hline \multicolumn{4}{|c|}{ Rheumatoid arthritis } \\
\hline Yes & $1779(5.6 \%)$ & $1789(5.6 \%)$ & \multirow[t]{2}{*}{0.86} \\
\hline No & $30,143(94.4 \%)$ & $30,133(94.4 \%)$ & \\
\hline \multicolumn{4}{|c|}{ Peptic ulcer disease } \\
\hline Yes & $10,512(32.9 \%)$ & $10,402(32.6 \%)$ & \multirow[t]{2}{*}{0.35} \\
\hline No & $21,410(67.1 \%)$ & $21,520(67.4 \%)$ & \\
\hline \multicolumn{4}{|c|}{ Liver disease } \\
\hline Yes & $6378(20.0 \%)$ & $6263(19.6 \%)$ & \multirow[t]{2}{*}{0.25} \\
\hline No & $25,544(80.0 \%)$ & $25,659(80.4 \%)$ & \\
\hline \multicolumn{4}{|c|}{ Diabetes mellitus } \\
\hline Yes & 8547 (26.8\%) & $8434(26.4 \%)$ & \multirow[t]{2}{*}{0.31} \\
\hline No & $23,375(73.2 \%)$ & $23,488(73.6 \%)$ & \\
\hline \multicolumn{4}{|c|}{ Hemiplegia or Paraplegia } \\
\hline Yes & $677(2.1 \%)$ & $640(2.0 \%)$ & \multirow[t]{2}{*}{0.30} \\
\hline No & 31,245 (97.9\%) & $31,282(98.0 \%)$ & \\
\hline \multicolumn{4}{|c|}{ Renal disease } \\
\hline Yes & $644(2.0 \%)$ & $622(2.0 \%)$ & \multirow[t]{2}{*}{0.53} \\
\hline No & 31,278 (98.0\%) & $31,300(98.0 \%)$ & \\
\hline \multicolumn{4}{|c|}{ Malignancy } \\
\hline Yes & $2915(9.1 \%)$ & $2938(9.2 \%)$ & \multirow[t]{2}{*}{0.75} \\
\hline No & 29,007 (90.9\%) & $28,984(90.8 \%)$ & \\
\hline \multicolumn{4}{|l|}{ HIV } \\
\hline Yes & $3(0.01 \%)$ & $2(0.02)$ & \multirow[t]{2}{*}{0.65} \\
\hline No & 31,919 (99.9\%) & 31,920 (99.99\%) & \\
\hline
\end{tabular}

Abbreviations: NPE Neuropsyhciatric event, SD Standard Deviation, CCI Charlson Comorbidity Index, LTMA Leukotriene Modifying Agent, HIV Human Immunodeficiency Virus

Chi-square test was used for categorical variables, $t$-test was used for numerical variables.

Table 2 Crude and adjusted odd ratios of leukotriene modifying agent exposure

\begin{tabular}{lllll}
\hline & Overall NPEs & Sleep disorder & Mood disorder & Anxiety disorder \\
\hline Crude OR $(95 \% \mathrm{Cl})$ & $1.58(1.50-1.68)$ & $1.50(1.38-1.63)$ & $1.49(1.37-1.63)$ & $1.53(1.41-1.66)$ \\
$p$ value & $<0.01$ & $<0.01$ & $<0.01$ & $<0.01$ \\
Adjusted $\mathrm{OR}^{\mathrm{a}}(95 \% \mathrm{Cl})$ & $1.67(1.58-1.78)$ & $1.54(1.42-1.68)$ & $1.65(1.51-1.81)$ & $1.63(1.50-1.77)$ \\
$p$ value & $<0.01$ & $<0.01$ & $<0.01$ & $<0.01$ \\
\hline
\end{tabular}

Abbreviations: NPE Neuropsychiatric Event, OR Odd Ratio, Cl Confidence Interval

${ }^{a}$ Adjusted by baseline characteristics in Table 1. Logistic regression was used in this analysis 
Table 3 Sub-group analysis, recency of exposure

\begin{tabular}{|c|c|c|c|c|c|c|c|c|}
\hline & \multicolumn{2}{|c|}{ Overall NPEs } & \multicolumn{2}{|c|}{ Sleep disorder } & \multicolumn{2}{|c|}{ Mood disorder } & \multicolumn{2}{|c|}{ Anxiety disorder } \\
\hline & OR & $\mathrm{Cl}$ & OR & $\mathrm{Cl}$ & OR & $\mathrm{Cl}$ & OR & $\mathrm{Cl}$ \\
\hline \multicolumn{9}{|c|}{ Group 1 (0-60 days) } \\
\hline Crude OR & 1.88 & $1.72-2.07$ & 1.80 & $1.58-2.05$ & 1.81 & $1.57-2.08$ & 1.92 & $1.68-2.19$ \\
\hline Adjusted $^{\mathrm{a}} \mathrm{OR}$ & 1.99 & $1.81-2.18$ & 1.85 & $1.62-2.11$ & 2.00 & $1.73-2.30$ & 2.05 & $1.79-2.35$ \\
\hline \multicolumn{9}{|c|}{ Group 2 (61-120 days) } \\
\hline Crude OR & 1.54 & $1.34-1.76$ & 1.43 & $1.18-1.73$ & 1.40 & $1.14-1.72$ & 1.43 & $1.18-1.73$ \\
\hline Adjusted $^{\mathrm{a}} \mathrm{OR}$ & 1.63 & $1.42-1.86$ & 1.47 & $1.21-1.79$ & 1.55 & $1.26-1.91$ & 1.53 & $1.26-1.85$ \\
\hline \multicolumn{9}{|c|}{ Group 3 (> 120 days) } \\
\hline Crude OR & 1.38 & $1.27-1.50$ & 1.30 & $1.15-1.47$ & 1.30 & $1.15-1.48$ & 1.30 & $1.16-1.47$ \\
\hline Adjusted $^{\mathrm{a}} \mathrm{OR}$ & 1.46 & $1.34-1.59$ & 1.34 & $1.18-1.51$ & 1.44 & $1.27-1.64$ & 1.38 & $1.23-1.56$ \\
\hline
\end{tabular}

Abbreviations: NPE Neuropsychiatric Event, OR Odd Ratio, Cl Confidence Interval

${ }^{a}$ Adjusted by baseline characteristics in Table 2. Logistic regression was used in this analysis. All analyses have $p$ value under 0.05

LTMAs. In this nested case-control study, asthma patients treated with LTMAs had 1.68 times higher risk of NPEs compared to asthma patients not treated with LTMAs, after controlling for socio-demographic factors and comorbidities. Among the risk of specific NPEs, the risk of anxiety disorder risk was the highest, but the difference was slight.

Our data on the association between NPEs and LTMA exposure are consistent with the results of several studies. Most of these previous studies were adverse drug reaction (ADR) studies using surveillance reports. A drug safety study that used data from the FDA Adverse Events Reporting System from 1999 to 2009 found that rates of reported completed suicides associated with montelukast increased substantially following warnings issued by the FDA [17]. Using a mixed-effects Poisson regression model, the authors found that empirical Bayes rates of patients treated with LTMAs were significantly greater than rates of patients treated with short-acting beta agonists. Haarman et al. [18] conducted an ADR study using the Netherlands Pharmacovigilance Center
Lareb and VigiBase, the WHO Global database. In VigiBase, depression, insomnia and anxiety had higher reporting odds ratios (ROR) compared to other adverse drug reaction reports in the database (depression: ROR 6.93, 95\% CI 6.54-7.36; insomnia; ROR 5.08, 95\% CI 4.77-5.41; anxiety: ROR 5.11, 95\% CI 4.79-5.41). In the Lareb database, insomnia and anxiety also had higher ROR compared to other drug adverse reaction reports (insomnia, ROR, 3.45; 95\% CI; 2.05-5.81, anxiety, ROR, 2.79; 95\% CI; 1.24-6.26), depression did not (ROR 1.91, 95\% CI 0.79-4.62). There was a case series on neuropsychiatric ADRs such as nightmares, hallucinations and sleep walking that disappeared after discontinuation of montelukast [19]. Schumock et al. [20] conducted a nested case control study using an insurance claims database on suicide, which are a type of NPEs, and found that the risk of suicide attempt increased with LTMA users aged in 19-24year in comparison with LTMA non users (adjusted OR: 5.15, 95\% CI 1.16-22.86). Based on these studies, NPEs can be significantly increased with LTMA treatment in adults.

Table 4 Sub-group analysis, duration of drug use

\begin{tabular}{|c|c|c|c|c|c|c|c|c|}
\hline & \multicolumn{2}{|c|}{ Overall NPEs } & \multicolumn{2}{|c|}{ Sleep disorder } & \multicolumn{2}{|c|}{ Mood disorder } & \multicolumn{2}{|c|}{ Anxiety disorder } \\
\hline & OR & $\mathrm{Cl}$ & OR & $\mathrm{Cl}$ & OR & $\mathrm{Cl}$ & OR & $\mathrm{Cl}$ \\
\hline \multicolumn{9}{|c|}{ Group 4 (0-30 days) } \\
\hline Crude OR & 1.58 & $1.47-1.69$ & 1.50 & $1.36-1.66$ & 1.44 & $1.30-1.60$ & 1.51 & $1.37-1.67$ \\
\hline Adjusted $^{\mathrm{a}} \mathrm{OR}$ & 1.67 & $1.56-1.79$ & 1.54 & $1.37-1.71$ & 1.61 & $1.44-1.79$ & 1.61 & $1.46-1.78$ \\
\hline \multicolumn{9}{|c|}{ Group 5 (31-120 days) } \\
\hline Crude OR & 1.63 & $1.47-1.92$ & 1.53 & $1.27-1.85$ & 1.67 & $1.36-2.05$ & 1.76 & $1.46-2.14$ \\
\hline Adjusted $^{a}$ OR & 1.77 & $1.55-2.03$ & 1.58 & $1.31-1.90$ & 1.83 & $1.49-2.26$ & 1.37 & $1.54-2.27$ \\
\hline \multicolumn{9}{|c|}{ Group 6 (> 120 days) } \\
\hline Crude OR & 1.51 & $1.31-1.75$ & 1.45 & $1.17-1.81$ & 1.53 & $1.23-1.90$ & 1.34 & $1.09-1.66$ \\
\hline Adjusted ${ }^{a} \mathrm{OR}$ & 1.60 & $1.38-1.85$ & 1.45 & $1.20-1.86$ & 1.63 & $1.36-2.09$ & 1.44 & $1.17-1.78$ \\
\hline
\end{tabular}

Abbreviations: NPE Neuropsychiatric Event, OR Odd Ratio, Cl Confidence Interval

${ }^{a}$ Adjusted by baseline characteristics in Table 2. Logistic regression was used in this analysis. All analyses have $p$ value under 0.05 
There were several studies that involved children. A nested case control study conducted by Glockler-Lauf et al. in Canada [21] showed that children with asthma who experienced a new-onset NPE had nearly double odds of having been prescribed montelukast in the year before the event (adjusted OR 1.91, 95\% CI 1.15-3.18) [21] . Furthermore, according to Benard et al. [22], the relative risk of neuropsychiatric ADRs in children (as reported by parents) associated with montelukast versus inhaled corticosteroid was 12.0 (95\% CI 1.6-90.2) [22].

On the other hand, in a nested case control study conducted by Schumock et al. [20], risk of suicide attempt in LTMA user had no significant correlation compared to patients who had never used LTMAs within age 511 years (adjusted OR 0.78, 95\% CI 0.03-19.09) and $12-18$ years (adjusted OR 0.47, 95\% CI 0.20-1.09). A US observational study conducted by Mir et al. in 2015 [6] found that there was no consistent significant association between montelukast and NPEs. Any exposure to montelukast from past 30 days to past 365 days did not affect the OR of NPEs compared to non-exposed patients (past 30 days: adjusted OR, 1.02, 95\% CI 0.82-1.26; past 90 days: adjusted OR, $1.00,95 \%$ CI $0.82-1.22$; past 180 days: adjusted OR, $0.99,95 \%$ CI 0.83-1.19; past 365 days: adjusted OR, $0.96,95 \%$ CI $0.80-1.14)$ [6]. These various studies have revealed inconsistent results about the risk of NPE in children after exposure to LTMAs. This could be due to the differences in patient population and changes of guidelines including LTMAs over time.

Although the molecular mechanism of association between NPEs and LTMAs remains unclear, there are several preclinical studies on the action of LTMAs in the brain and CNS. LTMAs (montelukast, pranlukast and zafirlukast) are anti-inflammatory drugs that specifically block the cysteinyl leukotriene type 1 (CysLT1) receptor [23]. By blocking this receptor, the drugs prevent the effects of CysLTs (LTC4, LTD4 and LTE4), which act to recruit inflammatory cells and increase vascular permeability [24]. Leukotrienes do not cross the blood-brain barrier (BBB) in any appreciable amounts; they are generated in brain tissue [25], and LTMAs, which can penetrate the $\mathrm{BBB}$, reduce the neuro-inflammatory action of leukotrienes in the brain by blocking their receptor $[26$, 27]. This neuroprotective effect of LTMAs can ameliorate surgery-induced brain injury and protect against disruption of brain endothelial junction protein according to a murine study [28]. Also, knockdown of hippocampal CysLT1 receptor in mice prevents chronic mild stressinduced depressive-like behaviors and neuroinflammation by preventing the increases in hippocampal NF- $\mathrm{kB}$, p65, IL-1 $\beta$, and TNF- $\alpha$ [29]. While binding to the cysLT1 receptor, LTMAs can produce nitric oxides, which are toxic to brain tissue and damage it [30-32]; these data are consistent with an increase in NPE risk by LTMAs. Although FDA requires boxed warning and several studies of ADRs showed that LTMAs can increase the risk of NPEs, the results of preclinical studies, have been inconsistent. Thus, to obtain pharmacological evidence, more studies focused on the action of leukotrienes and LTMAs in CNS will be needed.

In our analysis of recency of exposure, the effect of increasing NPE risk was maintained until at least 1 year from taking LTMAs. In every NPE analysis, the risk in the early period (group 1) was the highest among the periods. Thus, we recommend to pay attention to ADRs, especially mood disorder and anxiety disorder, immediately after discontinuing LTMA treatment.

In regard to the duration of drug use, the risk of NPEs was highest in group 5 (31-120 days) and decreased after 120 days of treatment. We infer that if the treatment is continued over 120 days, BBB permeability of LTMAs may decrease slightly because of some kind of a defense mechanism for protecting the brain. However, although montelukast can reportedly decrease $\mathrm{BBB}$ permeability in rats [33], studies on BBB permeability of LTMAs in are scarce in human.

This study has several limitations. The NHIS database does not provide detailed information about asthma severity (e.g. how often reliever medication is used in a week, number of acute symptoms at night). Although some studies suggest that severe asthma or poor asthma control can increase the risk of NPEs such as depression and self-harm [21, 34-36], some factors such as FEV1 that reflect asthma severity could not be examined in our study. To make up for this, we performed 1:1 matching within asthma patients. Despite these limitations, this study also has several important strengths. First, we used the NHIS elderly cohort which includes 554,147 elderly patients. This large-scale patient database reflects clinical practice in real-world patients and enhances the statistical power in examining the outcome, thus enhancing the accuracy of the study. Second, this database guarantees the representativeness of the elderly in South Korea because it covers $99 \%$ of the Korean population. Because National Health Insurance provides lifetime coverage for South Korean citizens, the rate of dropout was low and the risk of selection bias was minimized. Third, to clarify the association between LTMAs and NPEs, we matched by propensity score that included 21 variables (5 socio-demographic variables, 16 comorbidity variables). Neuropsychiatric diseases have many confounders, which may hamper efforts to define the association between specific variables. By propensity score matching, we minimized the effect of confounders. Lastly, until now, there has been no observational study on the link between NPE risk and LTMA treatment in elderly asthma patients. Therefore, this research provides 
the first evidence for the need to care about elderly asthma patient's neuropsychiatric ADRs.

\section{Conclusion}

This study suggests that elderly asthma patients prescribed LTMAs had a higher risk of NPEs than patients who were not treated with LTMAs. The risk was highest within 60 days after taking LTMAs. The risk of all three specific NPEs (sleep disorder, mood disorder, anxiety disorder) was increased by LTMA treatment in every recency and duration of drug treatment. Therefore, clinicians should be aware of the potential risks of NPEs, especially in the early stages of LTMA treatment.

\begin{abstract}
Abbreviations
ADR: Adverse drug reaction; BBB: Blood brain barrier; CCl: Charlson comorbidity index; Cl: Confidence interval; CysLT: Cysteinyl leukotriene; FDA: Food and drug administration in united states; HR: Hazard ratio; ICD10: International classification of disease, tenth revision; ICS: Inhaled corticosteroid; LT: Leukotriene; LTMA: Leukotriene modifying agent; NHIS: National health insurance service; NPE: Neuropsychiatric event; OR: Odds ratio; ROR: Reporting odd ratio; HIV: Human Immunodeficiency Virus
\end{abstract}

\section{Acknowledgements}

Not applicable

\section{Authors' contributions}

SOK, KHM, KEL designed the study. SOK, KHM, THK analyzed data. SOK, KHM, HJK, WK interpreted result. SOK and KHM drafted the manuscript. KEL supervised the project and made critical revisions in the manuscript. All authors read and approved the final manuscript.

\section{Funding}

This work was supported by the Basic Science Research Program through NRD funded by the Korea government (MSIP; Ministry of Science, ICT \& Future Planning) (NRF-2017R1C1B5016202). The funding sources did not have a role in the design, conduct, and analysis of the study.

\section{Availability of data and materials}

The datasets used and/or analyzed during the current study are available from the corresponding author on reasonable request.

\section{Declarations}

\section{Ethics approval and consent to participate}

Medical claims data from NHIS are available for public access. Data are encrypted to protect personal information and are provided with anonymous identification numbers. This study was approved by the Institutional Review of Chungbuk National University (CBNU-201703-ETC-42501).

\section{Consent for publication}

Not applicable.

\section{Competing interests}

The authors declare that they have no competing interests.

\section{Received: 2 February 2021 Accepted: 8 March 2021}

Published online: 17 March 2021

\section{References}

1. GBD 2015 Chronic Respiratory Disease Collaborators. Global, regional, and national deaths, prevalence, disability-adjusted life years, and years lived with disability for chronic obstructive pulmonary disease and asthma, 19902015: A systematic analysis for the global burden of disease study 2015. Lancet Respir Med. 2017;5:691-706.
2. Reddel HK, Bateman ED, Becker A, Boulet LP, Cruz AA, Drazen JM, Haahtela T, Hurd SS, Inoue H, de Jongste JC, Lemanske RF Jr, Levy ML, O'Byrne PM, Paggiaro P, Pedersen SE, Pizzichini E, Soto-Quiroz M, Szefler SJ, Wong GWK, FitzGerald JM. A summary of the new GINA strategy: a roadmap to asthma control. Eur Respir J. 2015;46(3):622-39. https://doi.org/10.1183/13993003. 00853-2015.

3. Boulet L, FitzGerald JM, Reddel HK. The revised 2014 GINA strategy report. Curr Opin Pulm Med. 2015;21(1):1-7. https://doi.org/10.1097/MCP. 0000000000000125

4. Balzano G, Fuschillo S, Gaudiosi C. Leukotriene receptor antagonists in the treatment of asthma: An update. Allergy. 2002;57(Suppl 72):16-9. https://doi. org/10.1034/j.1398-9995.57.s72.2.x.

5. Buccellati C, Fumagalli F, Viappiani S, Folco G. Leukotriene modifiers: novel therapeutic opportunities in asthma. Farmaco. 2002;57(3):235-42. https://doi. org/10.1016/50014-827X(02)01209-0.

6. Ali MM, O'Brien CE, Cleves MA, Martin BC. Exploring the possible association between montelukast and neuropsychiatric events among children with asthma: a matched nested case-control study. Pharmacoepidemiol Drug Saf. 2015;24(4):435-45. https://doi.org/10.1002/pds.3758.

7. FDA Drug Safety Communication. FDA requires boxed warning about serious mental health side effects for asthma and allergy drug montelukast (Singulair); advises restricting use for allergic rhinitis. 2020. Available from: https://www.fda.gov/media/135840/download.

8. Lee E, Kim A, Ye YM, Choi SE, Park HS. Increasing prevalence and mortality of asthma with age in Korea, 2002-2015: a nationwide, population-based study. Allergy Asthma Immunol Res. 2020;12(3):467-84. https://doi.org/10.41 68/aair.2020.12.3.467.

9. Djernes JK. Prevalence and predictors of depression in populations of elderly: a review. Acta Psychiatr Scand. 2006;113(5):372-87. https://doi.org/1 0.1111/j.1600-0447.2006.00770.x.

10. Gulia KK, Kumar VM. Sleep disorders in the elderly: a growing challenge. Psychogeriatrics. 2018;18(3):155-65. https://doi.org/10.1111/psyg.12319.

11. Ernster VL. Nested case-control studies. Prev Med. 1994;23(5):587-90. https:// doi.org/10.1006/pmed.1994.1093.

12. Chang Y. Practical guideline of asthma management - Korean guideline for asthma 2015. Korean J Med. 2016;90(4):298-306. https://doi.org/10.3904/ kjm.2016.90.4.298

13. Merck \& Co. Inc. Singulair (montelukast sodium) product label. 2020 Available from: https:/www.merck.com/product/usa/pi_circulars/s/singulair/ singulair_pi.pdf.

14. 김경훈. 건강보험청구자료에서 동반질환 보정방법. 보건행정학회지 2016;26:71-8.

15. Peacock J, Whang W. Psychological distress and arrhythmia: risk prediction and potential modifiers. Prog Cardiovasc Dis. 2013;55(6):582-9. https://doi. org/10.1016/j.pcad.2013.03.001

16. Dallé E, Mabandla MV. Early life stress, depression and parkinson's disease: a new approach. Mol Brain. 2018;11(1):18-9. https://doi.org/10.1186/s13041-01 8-0356-9.

17. Schumock GT, Gibbons RD, Lee TA, Joo MJ, Stayner LT, Valuck RJ. The association between leukotriene-modifying agents and spontaneously reported suicide. Drug Inf J. 2012;46(1):99-106. https://doi.org/10.1177/0092 861511427856.

18. Haarman MG, van Hunsel F, de Vries TW. Adverse drug reactions of montelukast in children and adults. Pharmacol Res Perspect. 2017;5(5): e00341. https://doi.org/10.1002/prp2.341.

19. Calapai G, Casciaro M, Miroddi M, Calapai F, Navarra M, Gangemi S. Montelukastinduced adverse drug reactions: a review of case reports in the literature. Pharmacology. 2014;94(1-2):60-70. https:/doi.org/10.1159/000366164.

20. Schumock GT, Stayner LT, Valuck RJ, Joo MJ, Gibbons RD, Lee TA. Risk of suicide attempt in asthmatic children and young adults prescribed leukotriene-modifying agents: a nested case-control study. J Allergy Clin Immunol. 2012;130(2):368-75. https://doi.org/10.1016/j.jaci.2012.04.035.

21. Glockler-Lauf S, Finkelstein Y, Zhu J, Feldman L, To T. Montelukast and neuropsychiatric events in children with asthma: a nested case-control study. J Pediatr. 2019;209:11-21.

22. Benard B, Bastien V, Vinet B, Yang R, Krajinovic M, Ducharme FM. Neuropsychiatric adverse drug reactions in children initiated on montelukast in real-life practice. Eur Respir J. 2017:50(2):1700148. https://doi. org/10.1183/13993003.00148-2017.

23. Scichilone N, Battaglia S, Benfante A, Bellia V. Safety and efficacy of montelukast as adjunctive therapy for treatment of asthma in elderly 
patients. Clin Interv Aging. 2013;8:1329-37. https://doi.org/10.2147/CIA.S3 5977.

24. Jo-Watanabe A, Okuno T, Yokomizo T. The role of leukotrienes as potential therapeutic targets in allergic disorders. Int J Mol Sci. 2019;20(14):3580. https://doi.org/10.3390/ijms20143580.

25. Feuerstein $\mathrm{G}$, Hallenbeck JM. Leukotrienes in health and disease. FASEB J. 1987;1(3):186-92. https://doi.org/10.1096/fasebj.1.3.3040505.

26. Price D. Tolerability of montelukast. Drugs. 2000;59(Suppl 1):35-42. https:// doi.org/10.2165/00003495-200059001-00006.

27. Marschallinger J, Schäffner I, Klein B, Gelfert R, Rivera FJ, Illes S, Grassner L, Janssen M, Rotheneichner P, Schmuckermair C, Coras R, Boccazzi M, Chishty M, Lagler FB, Renic M, Bauer HC, Singewald N, Blümcke I, Bogdahn U, Couillard-Despres S, Lie DC, Abbracchio MP, Aigner L. Structural and functional rejuvenation of the aged brain by an approved anti-asthmatic drug. Nat Commun. 2015:6(1):8466. https://doi.org/10.1038/ncomms9466.

28. Zhou L, Sun X, Shi Y, Liu J, Luan G, Yang Y. Cysteinyl leukotriene receptor type 1 antagonist montelukast protects against injury of blood-brain barrier. Inflammopharmacology. 2019;27(5):933-40. https://doi.org/10.1007/ s10787-019-00611-7.

29. Yu XB, Dong RR, Wang H, Lin JR, An YQ, Du Y, et al. Knockdown of hippocampal cysteinyl leukotriene receptor 1 prevents depressive behavior and neuroinflammation induced by chronic mild stress in mice. Psychopharmacology (Berl). 2016;233:1739-49.

30. Schumock G, Lee T, Joo M, Valuck R, Stayner L, Gibbons R. Association between leukotriene-modifying agents and suicide. Drug-Safety. 2011;34(7): 533-44. https://doi.org/10.2165/11587260-000000000-00000.

31. Khalid F, Aftab A, Khatri S. The association between leukotriene-modifying agents and suicidality: a review of literature. Psychosomatics (Washington, D.C.). 2018;59:19-27.

32. Maes M, Bonifacio KL, Morelli NR, Vargas HO, Moreira EG, St. Stoyanov D, Barbosa DS, Carvalho AF, Nunes SOV. Generalized anxiety disorder (GAD) and comorbid major depression with GAD are characterized by enhanced nitro-oxidative stress, increased lipid peroxidation, and lowered lipidassociated antioxidant defenses. Neurotox Res. 2018;34(3):489-510. https:// doi.org/10.1007/s12640-018-9906-2.

33. Biber N, Toklu HZ, Solakoglu S, Gultomruk M, Hakan T, Berkman Z, et al. Cysteinyl-leukotriene receptor antagonist montelukast decreases bloodbrain barrier permeability but does not prevent oedema formation in traumatic brain injury. Brain Inj. 2009;23(6):577-84. https://doi.org/10.1080/02 699050902926317

34. Goodwin RD, Marusic A. Asthma and suicidal ideation among youth in the community. Crisis. 2004;25(3):99-102. https://doi.org/10.1027/0227-5910.25.3.99.

35. Choi G, Shin YS, Kim J, Choi SY, Lee S, Nam Y, et al. Prevalence and risk factors for depression in korean adult patients with asthma: is there a difference between elderly and non-elderly patients? J Korean Med Sci. 2014;29(12):1626-31. https://doi.org/10.3346/jkms.2014.29.12.1626.

36. Goodwin RD, Jacobi F, Thefeld W. Mental disorders and asthma in the community. Arch Gen Psychiatry. 2003;60(11):1125-30. https://doi.org/10.1 001/archpsyc.60.11.1125.

\section{Publisher's Note}

Springer Nature remains neutral with regard to jurisdictional claims in published maps and institutional affiliations.

Ready to submit your research? Choose BMC and benefit from:

- fast, convenient online submission

- thorough peer review by experienced researchers in your field

- rapid publication on acceptance

- support for research data, including large and complex data types

- gold Open Access which fosters wider collaboration and increased citations

- maximum visibility for your research: over $100 \mathrm{M}$ website views per year

At BMC, research is always in progress.

Learn more biomedcentral.com/submissions 